Supplementary Information

for

21

\title{
Efficient Photocatalytic PFOA Degradation Over Boron Nitride
}

Lijie Duan, ${ }^{1,2,3,4 \dagger}$ Bo Wang, ${ }^{3,4 \dagger}$ Kimberly Heck, ${ }^{3,4}$ Sujin Guo, ${ }^{4,5}$ Chelsea A. Clark, ${ }^{3,4}$ Jacob Arredondo, ${ }^{3}$ Minghao Wang, ${ }^{1,2}$ Thomas P. Senftle, ${ }^{3}$ Paul Westerhoff,,${ }^{4,6}$ Xianghua Wen, ${ }^{1}$ Yonghui Song, ${ }^{1,2^{*}}$ Michael S. Wong ${ }^{3,4,5,7,8^{*}}$

${ }^{1}$ School of Environment, Tsinghua University, Beijing 100084, China

${ }^{2}$ State Key Laboratory of Environmental Criteria and Risk Assessment, Chinese Research Academy of Environmental Sciences, Beijing 100012, China

${ }^{3}$ Department of Chemical and Biomolecular Engineering, Rice University, Houston, TX 77005, USA

${ }^{4}$ Nanosystems Engineering Research Center for Nanotechnology-Enabled Water Treatment, Houston, TX 77005, USA

${ }^{5}$ Department of Environmental Engineering, Rice University, Houston, TX 77005, USA

${ }^{6}$ School of Sustainable Engineering and Built Environment, Arizona State University, Tempe, AZ 85281, USA

${ }^{7}$ Department of Chemistry, Rice University, Houston, TX 77005, USA

${ }^{8}$ Department of Materials Science and NanoEngineering, Rice University, Houston, TX 77005, USA

†These authors contributed equally to the manuscript

*Corresponding authors: mswong@rice.edu and songyh@craes.org.cn 
25 Table S1. Comparison of reported literature values of PFOA photocatalysts using UVC irradiation.

\begin{tabular}{|c|c|c|c|c|c|c|c|c|c|}
\hline $\begin{array}{c}\text { PFOA } \\
\text { concentration } \\
(\text { ppm })\end{array}$ & $\begin{array}{l}\text { Photocatalyst } \\
\text { (concentration) }\end{array}$ & $\begin{array}{c}\text { Band gap of } \\
\text { photocatalyst } \\
(\mathrm{eV})\end{array}$ & $\begin{array}{l}\text { Volume } \\
\text { Treated } \\
(\mathrm{mL})\end{array}$ & $\begin{array}{c}\text { Initial } \\
\text { pH }\end{array}$ & Illumination Source & $\begin{array}{c}\text { Spectral irradiance } \\
\left(\mathbf{m W} / \mathrm{cm}^{2}\right)\end{array}$ & $\begin{array}{c}\text { Reaction } \\
\text { Atmosphere }\end{array}$ & $\begin{array}{c}\text { Half-life } \\
\text { of } \\
\text { PFOA } \\
\text { (h) }\end{array}$ & Ref \\
\hline 50 & $\mathrm{TiO}_{2}(0.5 \mathrm{~g} / \mathrm{L})$ & Not reported & 80 & 6.0 & $\mathrm{UVC}(5 \mathrm{~W}, 254 \mathrm{~nm})$ & Not reported & Air & 23 & 1 \\
\hline 100 & $\mathrm{TiO}_{2}(0.5 \mathrm{~g} / \mathrm{L})$ & Not reported & 500 & 2.4 & UVC (23W, 254nm) & Not reported & $\mathrm{N}_{2}$ & 1 & 2 \\
\hline 1,656 & $\mathrm{TiO}_{2}(0.66 \mathrm{~g} / \mathrm{L})$ & Not reported & $\begin{array}{c}\text { Not } \\
\text { reported }\end{array}$ & 6.0 & $\begin{array}{c}\text { UVC, UVB }(500 \mathrm{~W} \\
310-400 \mathrm{~nm})\end{array}$ & 95 & Air & 12 & 3 \\
\hline 50 & $\mathrm{TiO}_{2}$ nanotubes $(0.25 \mathrm{~g} / \mathrm{L})$ & Not reported & 2000 & 4 & UVC (400W, 254nm) & Not reported & Air & 26 & 4 \\
\hline 50 & $2 \mathrm{wt} \% \mathrm{~Pb}-\mathrm{TiO}_{2}(0.5 \mathrm{~g} / \mathrm{L})$ & 3.16 & $\begin{array}{c}\text { Not } \\
\text { reported }\end{array}$ & 3 & UVC (400W, 254nm) & Not reported & Air & 1.50 & 5 \\
\hline 60 & $1 \mathrm{wt} \% \mathrm{Pt}-\mathrm{TiO}_{2}(0.5 \mathrm{~g} / \mathrm{L})$ & 2.92 & 120 & 3.0 & $\begin{array}{c}\text { UVA }(165 \mathrm{~W}, 365 \\
\mathrm{nm})\end{array}$ & 5.3 & Air & 0.95 & 6 \\
\hline 50 & $1 \mathrm{wt} \% \mathrm{Cu}-\mathrm{TiO}_{2}(0.5 \mathrm{~g} / \mathrm{L})$ & 3.29 & $\begin{array}{c}\text { Not } \\
\text { reported }\end{array}$ & 5 & UVC (400W, 254nm) & Not reported & Air & 3.73 & 7 \\
\hline 50 & $\mathrm{~Pb}-\mathrm{BiFeO}_{3} / \mathrm{rGO}(0.1 \mathrm{~g} / \mathrm{L})$ & Not reported & 80 & 3.8 & $\mathrm{UVC}(5 \mathrm{~W}, 254 \mathrm{~nm})$ & Not reported & Air & 8.55 & 8 \\
\hline 10 & $\mathrm{BiOCl}(1 \mathrm{~g} / \mathrm{L})$ & 3.0 & 250 & 4.6 & UVC (10W, 254nm) & Not reported & Air & 1.43 & 9 \\
\hline 50 & $\mathrm{Bi}_{3} \mathrm{O}(\mathrm{OH})\left(\mathrm{PO}_{4}\right)_{2}(1.8 \mathrm{~g} / \mathrm{L})$ & 3.9 & $\begin{array}{l}\text { Not } \\
\text { reported }\end{array}$ & 4 & UVC (18W, 254nm) & Not reported & Air & 0.12 & 10 \\
\hline
\end{tabular}




\begin{tabular}{|c|c|c|c|c|c|c|c|c|c|}
\hline 40 & $\beta-\mathrm{Ga}_{2} \mathrm{O}_{3}(0.5 \mathrm{~g} / \mathrm{L})$ & 4.8 & 100 & 4.8 & UVC (15W, 254nm) & Not reported & $\mathrm{N}_{2}$ & 0.48 & 11 \\
\hline 50 & SiC/Graphene $(0.5 \mathrm{~g} / \mathrm{L})$ & Not reported & 80 & 6.0 & UVC (15W, 254nm) & Not reported & Air & 7.2 & 1 \\
\hline 50 & $\mathrm{Pt} 1 / \mathrm{SiC}(0.5 \mathrm{~g} / \mathrm{L})$ & Not reported & 80 & 6.0 & $\mathrm{UVC}(5 \mathrm{~W}, 254 \mathrm{~nm})$ & Not reported & Air & 0.35 & 12 \\
\hline 30 & $\mathrm{In}_{2} \mathrm{O}_{3}(0.5 \mathrm{~g} / \mathrm{L})$ & 3.6 & 100 & 3.9 & UVC (23W, 254nm) & Not reported & $\mathrm{O}_{2}$ & 0.12 & 13 \\
\hline 41.4 & $\mathrm{In}_{2} \mathrm{O}_{3}(0.5 \mathrm{~g} / \mathrm{L})$ & Not reported & 400 & 3.8 & UVC (23 W, 254 nm) & Not reported & $\mathrm{O}_{2}$ & 3.80 & 14 \\
\hline 20 & $\mathrm{InOOH}(0.25 \mathrm{~g} / \mathrm{L})$ & 3.7 & 200 & $\begin{array}{c}\text { Not } \\
\text { reported }\end{array}$ & UVC (18W, 254nm) & Not reported & Air & 1.44 & 15 \\
\hline 50 & $\mathrm{BN}(2.5 \mathrm{~g} / \mathrm{L})$ & 5.92 & 20 & 7.0 & UVC (24W, 254nm) & 3.8 & Air & 0.75 & This work \\
\hline 50 & $\mathrm{BN}(2.5 \mathrm{~g} / \mathrm{L})$ & 5.92 & 20 & 7.0 & UVC (4.8W, 254nm) & 1.94 & Air & 1.2 & This work \\
\hline 50 & $\mathrm{TiO}_{2}(0.5 \mathrm{~g} / \mathrm{L})$ & 3.32 & 20 & 6.0 & UVC (4.8W, 254nm) & 1.94 & Air & 3.0 & This work \\
\hline 50 & $\mathrm{BN}(2.5 \mathrm{~g} / \mathrm{L})$ & 5.92 & 20 & 3.0 & UVC (4.8W, 254nm) & 1.94 & Air & 1.0 & This work \\
\hline 50 & Ball-milled BN (2.5 g/L) & 5.62 & 20 & 3.0 & UVC (4.8W, 254nm) & 1.94 & Air & 0.75 & This work \\
\hline
\end{tabular}




\section{Text S1. Materials}

28 All materials were of analytical grade and used as received. Perfluorooctanoic acid $\left(\mathrm{C}_{7} \mathrm{~F}_{15} \mathrm{COOH}\right.$, $2996 \%$ purity), hexagonal boron nitride (BN, powder, $\sim 1 \mu \mathrm{m}, 98 \%$ purity, lot number STBH7651), 30 titanium dioxide $\left(\mathrm{TiO}_{2}, \mathrm{P} 25\right.$ nanopowder, $\sim 21 \mathrm{~nm}$ particle size, $\left.\geq 99.5 \%\right)$, silicon dioxide $\left(\mathrm{SiO}_{2}\right.$, 31 nanopowder, 10-20 nm particle size, 99.5\% purity), were obtained from Sigma-Aldrich. Deionized 32 water (DI water) was used in all experiments.

We note that different sources of BN can show different PFOA degradation activities. We

34 tested two different lots from the same product from Sigma Aldrich (i.e. BN, $1 \mu \mathrm{m}, 98 \%$ ): 1 lot 35 number STBJ0358 had minimal activity, but lot number STBJ3711 showed similar activity to the 36 material used in this work. Hypothesizing that the lower activity was due to a lower content of 37 surface defects, we took Raman spectra of the powders. We found that the FWHM for lot number 38 STBJ0358 was $\sim 10 \mathrm{~cm}^{-1}$, indicating that this material was relatively more defect-free than the one 39 presented in this manuscript. On the other hand, lot number STBJ3711 had a FWHM $\sim 12 \mathrm{~cm}^{-1}$, 40 which matches that in the manuscript. 


\section{Text S2. Methods}

43

44 Ball milling can introduce defects into BN. ${ }^{16,17}$ To prepare milled BN, $300 \mathrm{mg}$ of h-BN powder

45 and $10 \mathrm{mg}$ of $8 \mathrm{~mm} \mathrm{ZrO}_{2}$ balls were placed in the milling jar, then milled at $550 \mathrm{rpm}$ for 1 hour.

\subsection{Characterization}

47 The crystallite structures of $\mathrm{BN}$ and $\mathrm{TiO}_{2}$ were characterized using X-ray powder diffraction (XRD). Spectra (Figure S1) were collected on a Rigaku D/Max Ultima II diffractometer (40 kV,

$4940 \mathrm{~mA}$ ) using $\mathrm{Cu}-\mathrm{K} \alpha$ radiation, and were typical of reported $\mathrm{TiO}_{2}$ and h-BN. Transmission

50 electron microscopy (TEM) images were obtained using a JEOL 2010 TEM operating at an

51 accelerating voltage of $200 \mathrm{kV}$ and are shown in Figure S2. X-ray photoelectron spectroscopy

52 (XPS) data was obtained using a PHI Quantera System with monochromatic A1 KR radiation. XPS

53 samples were prepared by placing $50 \mathrm{mg}$ of material in an $80^{\circ} \mathrm{C}$ oven overnight to evaporate water

54 before analysis. DR-UV of the powders was obtained by diluting with $60 \mathrm{wt} \% \mathrm{BaSO}_{4}$, pressing

55 into a wafer, and measured using a Shimadzu UV-2450 spectrometer. Nitrogen physisorption was

56 performed following 5 hours of evacuation at $150^{\circ} \mathrm{C}$ and BET surface areas are shown in Table

57 S2. Raman spectra was collected from $100 \mathrm{~cm}^{-1}$ to $3200 \mathrm{~cm}^{-1}$ on a Raman microscope with 532

58 nm excitation. 


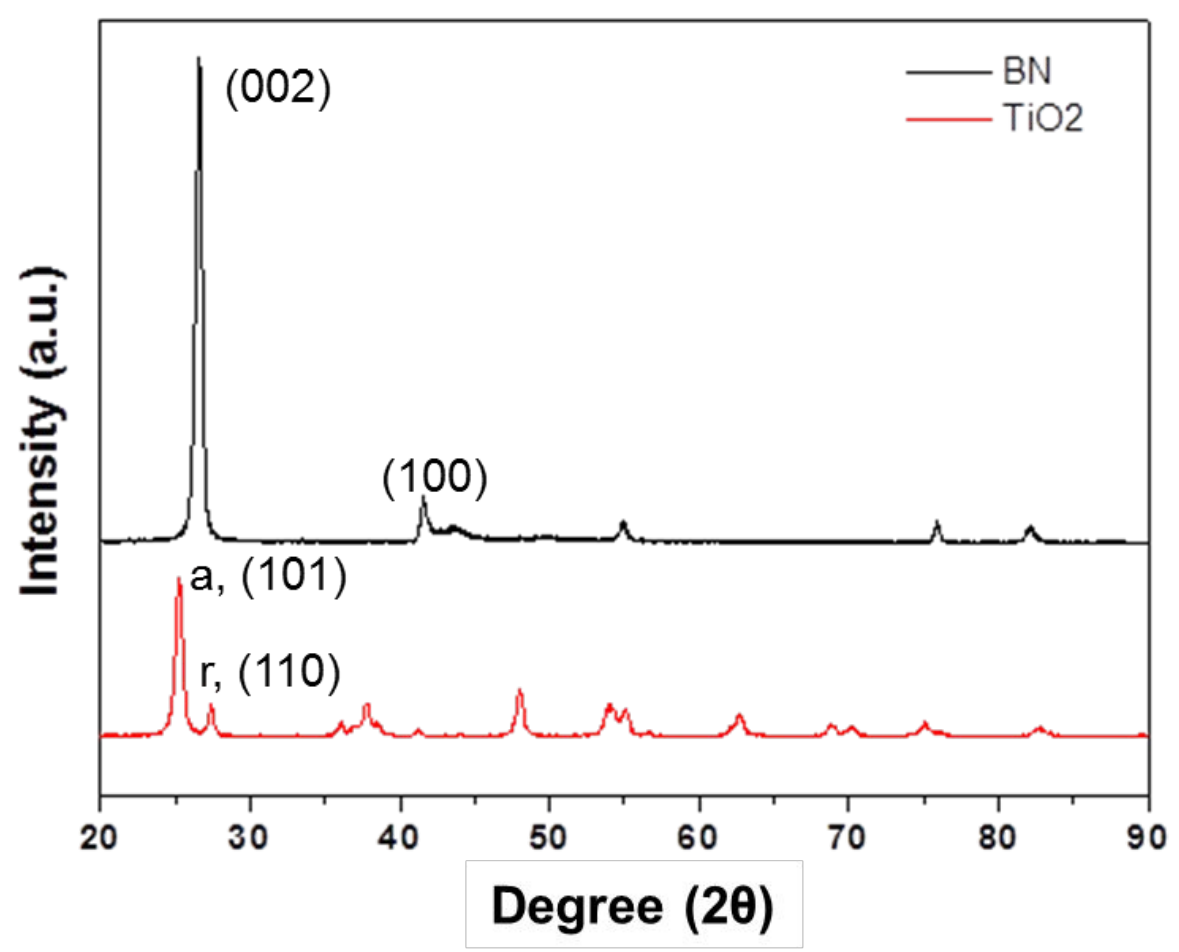

59

60 Figure S1. XRD spectra of hexagonal $\mathrm{BN}$ and $\mathrm{TiO}_{2}$; "a" and " $\mathrm{r}$ " refer to the anatase and rutile 61 phases of $\mathrm{P} 25-\mathrm{TiO}_{2}$.

62

63
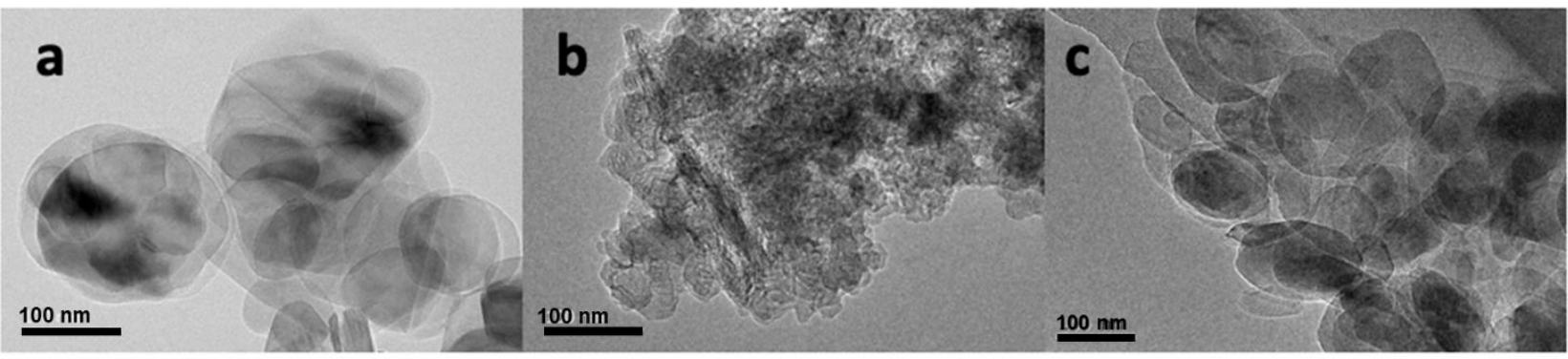

64 Figure S2. TEM of (a) as-received $\mathrm{BN}$, (b) $\mathrm{P} 25-\mathrm{TiO}_{2}$, and (c) ball-milled BN.

65 


\begin{tabular}{|c|c|}
\hline Material & BET surface area $\left(\mathrm{m}^{2} \mathrm{~g}^{-1}\right)$ \\
\hline $\mathrm{BN}-$ as received & 25 \\
\hline $\mathrm{TiO}_{2}$ & 49 \\
\hline $\mathrm{BN}-$ ball milled & 83 \\
\hline
\end{tabular}

68

69 


\section{Text S3. Photocatalytic procedure}

71 The photocatalytic reactor used was fabricated in-house and similar to that described by Alvarez

72 and coworkers. ${ }^{18,} 19$ It was equipped with six 4W UVC Ushio G4T5 low pressure mercury 73 germicidal lamps and a stir plate. The spectral irradiance values for our experimental system (Table

74 S1) were measured using a UVP UVX radiometer equipped with a $254 \mathrm{~nm}$ sensor placed on the 75 stir bar of the UV reactor. In a typical experiment, the optimum amount of photocatalyst $(2.5 \mathrm{~g} / \mathrm{L}$ $76 \mathrm{BN}$, or $0.5 \mathrm{~g} / \mathrm{L} \mathrm{TiO}_{2}$ ) was added to a $100 \mathrm{~mL}$ quartz round bottom flask containing $20 \mathrm{~mL}$ of DI $77 \mathrm{H}_{2} \mathrm{O}$ spiked with $50 \mathrm{ppm}(0.12 \mathrm{mM})$ PFOA and capped with a septum before placing in the reactor 78 box and turning on light and stirring. Initial $\mathrm{pH}$ for most experiments was 6.5. Aliquots were 79 removed and filtered with $0.20 \mu \mathrm{m}$ syringe filters. Optimal loadings (as recommended by others ${ }^{20}$, $80{ }^{21}$ ) of $\mathrm{BN}$ and $\mathrm{TiO}_{2}$ were determined by dosing the reactor with varied masses of photocatalyst, 81 then choosing the concentration at which the rate of PFOA disappearance was maximum (Figure $82 \mathrm{~S} 3$ ). Due to changes in $\mathrm{pH}$ with time, degradation rates were determined using only the first points 83 (i.e. $<60 \mathrm{~min}$ ) in the degradation profile. To assess possible leaching of $\mathrm{BN}$ or $\mathrm{TiO}_{2}$, select filtered 84 aliquots were analyzed by ICP-OES. No leached B, N, or Ti was detected. 
85

86

87

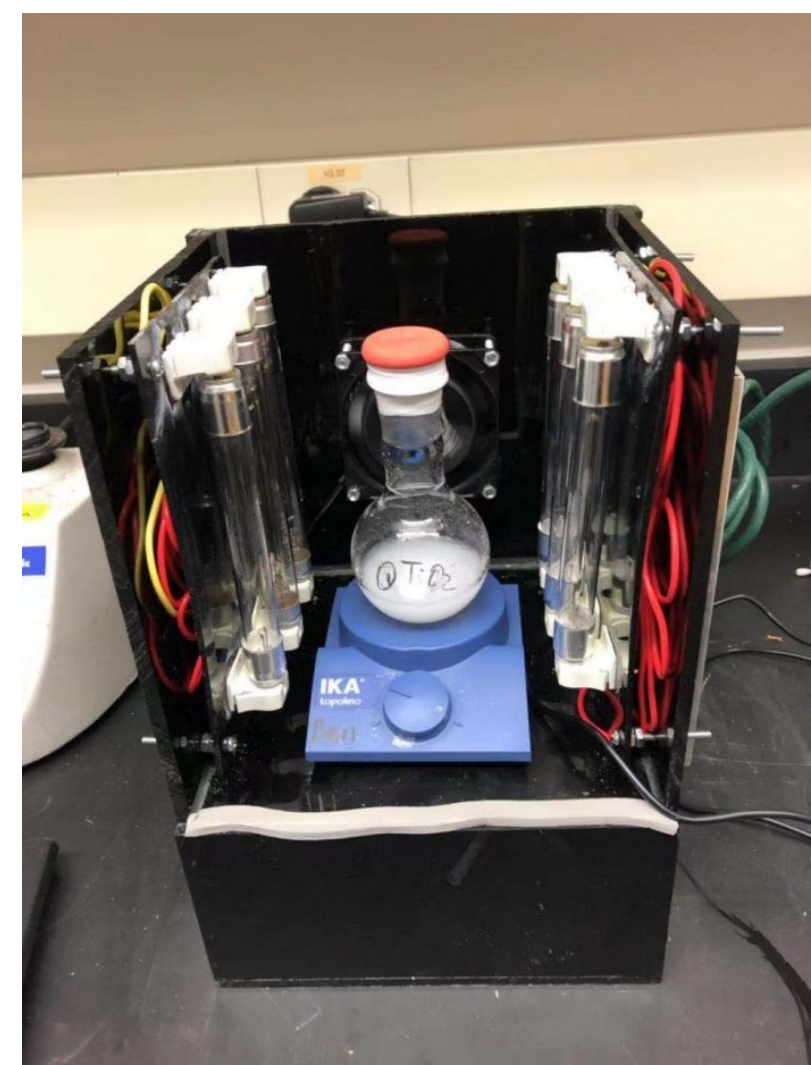

Scheme S1. Typical reaction set up (with lid removed). 

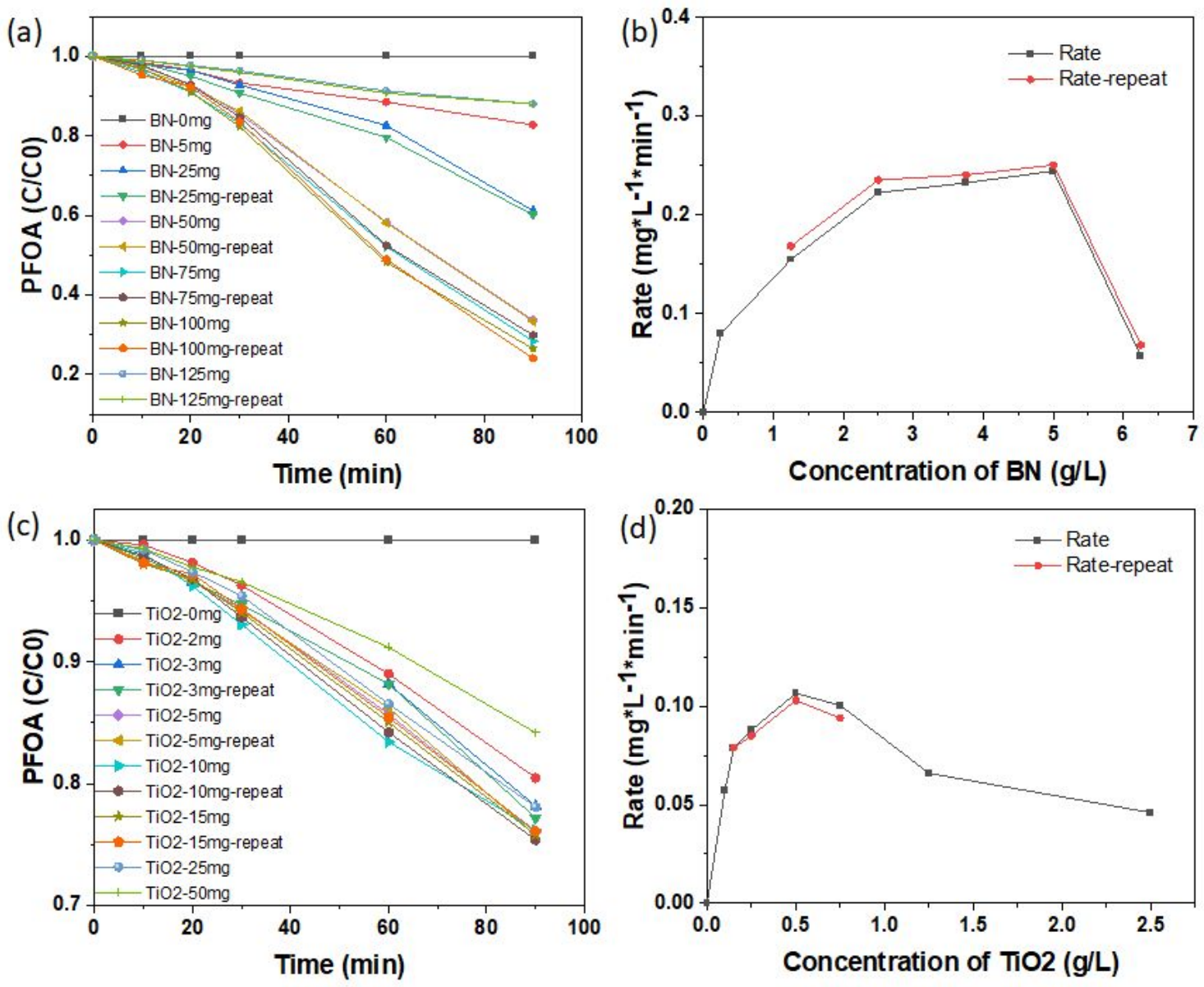

Figure S3. PFOA concentration vs time using various amounts of (a) $\mathrm{BN}$ and (c) $\mathrm{TiO}_{2}$, and rate

92 of reaction vs photocatalyst loading for (b) $\mathrm{BN}$ and (d) $\mathrm{TiO}_{2}$. Each loading was carried out twice,

93 showing nearly identical reaction rates.

94

Control experiments using identical conditions and shaking with 0-100 mg of BN without $254 \mathrm{~nm}$ illumination verified no removal of PFOA by adsorption (Figure S4). Negative control experiments using only $\mathrm{UVC}$ or $\mathrm{SiO}_{2}$ with UVC showed no degradation (Figure S5). 


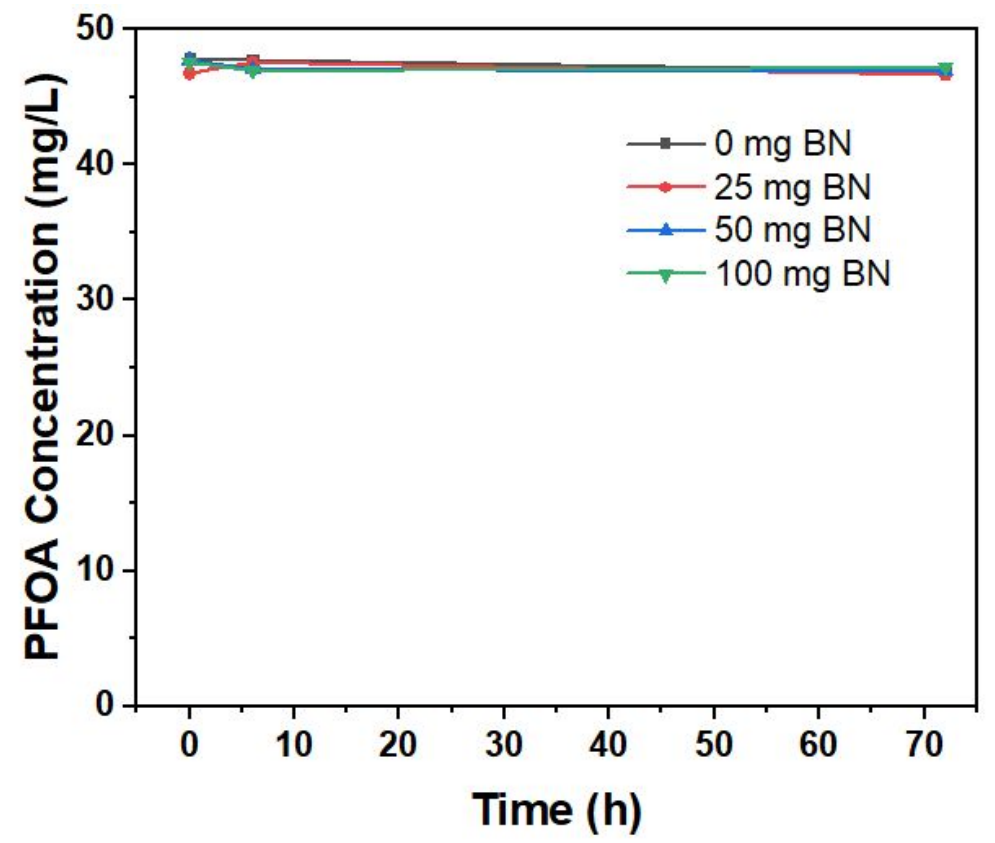

99 Figure S4. PFOA concentration vs time using various amounts of BN without $254 \mathrm{~nm}$ illumination.

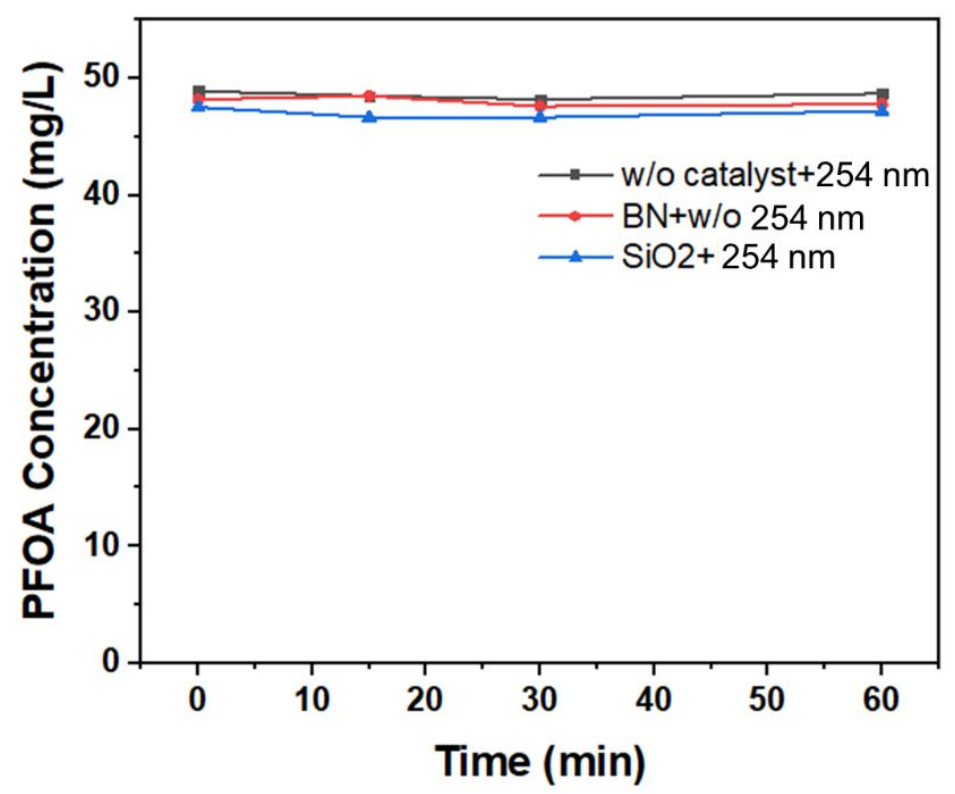

Figure S5. PFOA concentration vs time using only $254 \mathrm{~nm}$ light, $\mathrm{BN}$ without light, and $\mathrm{SiO}_{2}$ and $102254 \mathrm{~nm}$ light.

103 Scavenger experiments were done similar to the results presented in Figure 1, except using 3 $104 \mathrm{mM}$ of EDTA (initial $\mathrm{pH} \sim 4.5$ ), TBA (initial $\mathrm{pH} \sim 5$ ), or SOD (initial $\mathrm{pH} \sim 6$ ). For the ball-milled 105 and SDW experiments, initial $\mathrm{pH}$ was preacidified to $\sim 3.5$ for the ball-milled and SDW 
experiments to prevent large changes in $\mathrm{pH}$ observed in initial experiments, presumably due to $\mathrm{H}^{+}$ byproducts of hydroxyl radical production or the formation of shorter chain (lower $\mathrm{pK}_{\mathrm{a}}$ ) acids.

Experiments using terephthalic acid $(\bullet \mathrm{OH}$ probe $)$ also confirmed generation of the radicals

112 though quantification was complicated by adsorption of the hydrophobic dye and product to the

113 BN. However, the system turned purple typical of the formazon product (Figure S6b). ${ }^{22}$
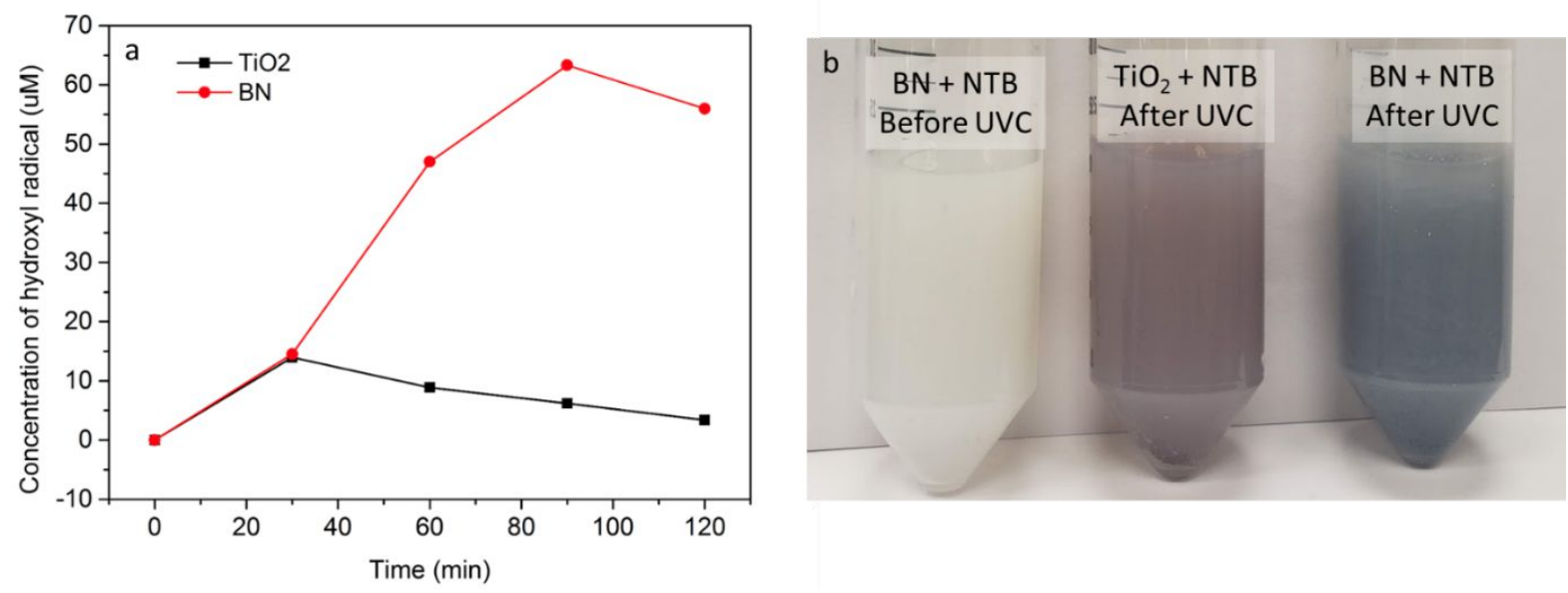

115 Figure S6. (a) Generation of hydroxyl radicals versus time over $\mathrm{BN}$ and $\mathrm{TiO}_{2}$; and (b) photo of reaction $\mathrm{BN}$ and NTB fluids before and following exposure to $254 \mathrm{~nm}$ light. 


\section{Text S4. Analytical methods}

120 The concentration of PFOA was determined by high-performance liquid chromatography with

121 diode array detector (HPLC-DAD, 1260 Infinity II Agilent, USA) with a WPH C18 column (4.6 $122 \mathrm{~mm} \times 250 \mathrm{~mm}, 5 \mu \mathrm{m})$. The mobile phase was $50 \mathrm{v} \%$ acetonitrile and $50 \mathrm{vol} \%$ of $5 \mathrm{mmol} \mathrm{L}^{-1}$ $123 \mathrm{Na}_{2} \mathrm{HPO}_{4}$ with a flow rate of $0.8 \mathrm{~mL} \mathrm{~min}^{-1}$, a sample injection volume of $50 \mu \mathrm{L}$, and detected at $124210 \mathrm{~nm}$. The concentration of released fluoride was measured by ion chromatography (IC, (Dionex 125 Aquion, $4 \times 250 \mathrm{~mm}$ IonPac AS23, AERS 500 Carbonate Suppressor). pH measurements were 126 recorded using an Orion Star A111 pH probe. adsorbed in the flasks in the photoreactor (Scheme S1) was done using standard methods. ${ }^{23}$ The

129 rate of photons adsorbed was determined to be $2.6 \mu \mathrm{Ein} / \mathrm{L} / \mathrm{s}$. Defining an apparent quantum yield 130 $(Q Y)$ as molecules of PFOA degraded per photon reaching the reaction fluid (eqn 1):24 where $\triangle[P F O A]$ is PFOA degraded in time interval $\Delta t, V$ is the reaction fluid volume, and $\gamma$ is the adsorbed photons in time interval $\Delta t$, as determined by chemical actinometry (Text S4), we

134 calculate that the $\mathrm{TiO}_{2}$, as-received $\mathrm{BN}$, and ball-milled $\mathrm{BN}$ have $Q Y \mathrm{~s}$ of $0.18 \%, 0.4 \%$, and $0.7 \%$, 135 respectively, i.e, as-received $\mathrm{BN}$ and ball-milled $\mathrm{BN}$ are roughly 2 and 4 times more photon136 efficient than $\mathrm{TiO}_{2}$. 
Table S3. Composition of Simulated Drinking Water (SDW)

\begin{tabular}{|c|c|}
\hline General Parameters & Specification \\
\hline $\mathrm{pH}($ adjusted with $\mathrm{HCl})$ & 3 \\
\hline Constituents & Concentration $(\mathrm{mg} / \mathrm{L})$ \\
\hline Bicarbonate $\left(\mathrm{HCO}_{3}{ }^{-}\right.$initial) & 183 \\
\hline Calcium $\left(\mathrm{Ca}^{2+}\right)$ & 70 \\
\hline Chloride $\left(\mathrm{Cl}^{-}\right)$ & 11 \\
\hline Fluoride $\left(\mathrm{F}^{-}\right)$ & 12 \\
\hline Magnesium $\left(\mathrm{Mg}^{2+}\right)$ & $8.9(2.0$ as $\mathrm{N})$ \\
\hline Nitrate $\left(\mathrm{NO}_{3}{ }^{-}\right)$ & $0.12(0.04$ as $\mathrm{P})$ \\
\hline Phosphate $\left(\mathrm{PO}_{4}{ }^{3-}\right)$ & 20 as $\mathrm{SiO}$ \\
\hline Silica $\left(\mathrm{SiO}_{2}\right)$ & 89 \\
\hline Sodium $\left(\mathrm{Na}^{+}\right)$ & 48 \\
\hline Sulfate $\left(\mathrm{SO}_{4}{ }^{2-}\right)$ & 478 \\
\hline Total Dissolved $\mathrm{Solids}^{(\mathrm{TDS})}$ & \\
\hline
\end{tabular}




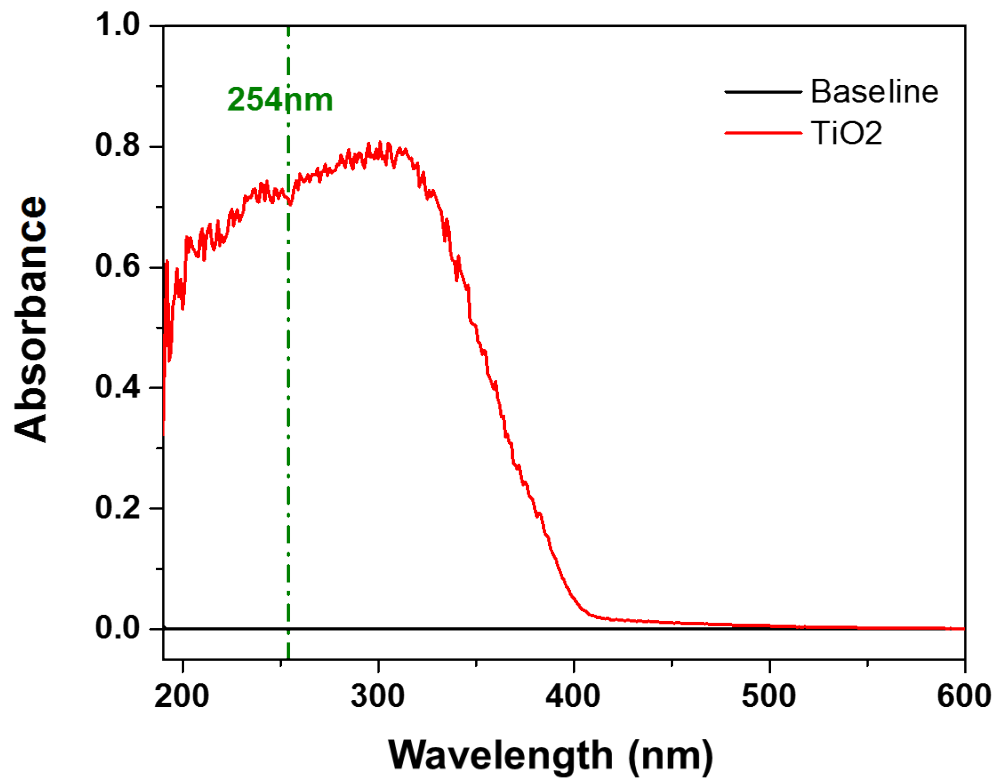

Figure S7. DR-UV spectrum of $\mathrm{TiO}_{2}$. 


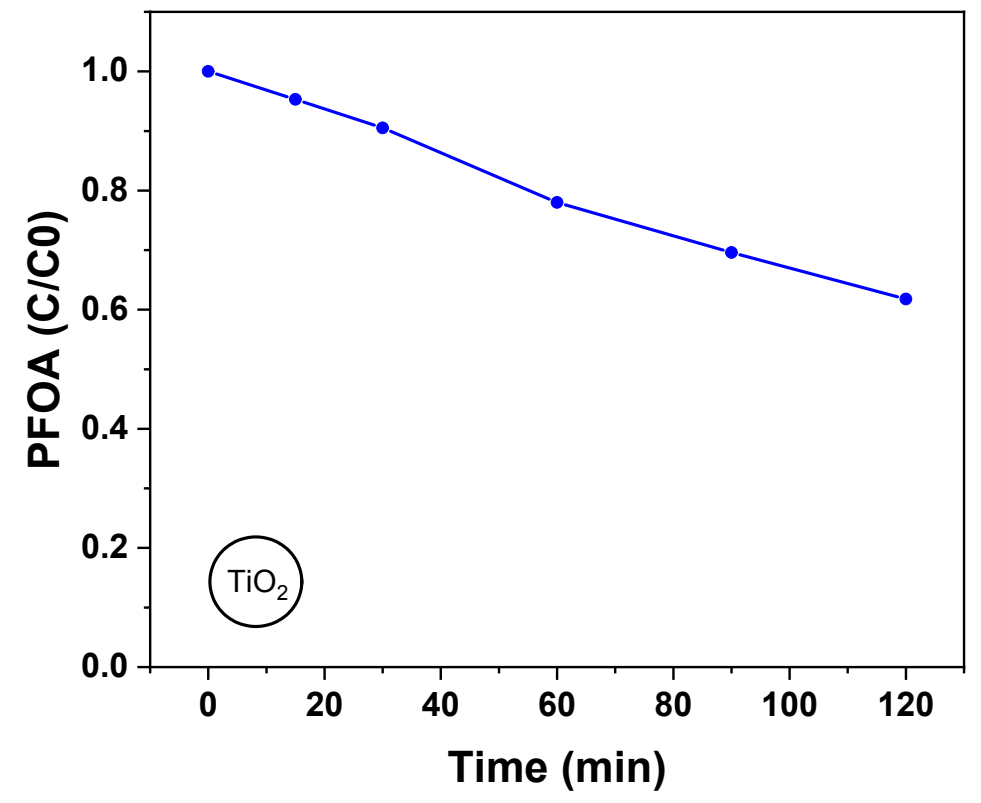

Figure S8. PFOA degradation vs time for $\mathrm{TiO}_{2}$. Reaction conditions: $[\mathrm{PFOA}]_{0}=\sim 50 \mathrm{v}$ ppm, dosage of $0.5 \mathrm{~g} / \mathrm{L} \mathrm{TiO}_{2}$, ambient temperature, air headspace, 254-nm light, initial $\mathrm{pH}=3.3$. 


\section{References}

1. Huang, D.; Yin, L.; Niu, J., Photoinduced hydrodefluorination mechanisms of perfluorooctanoic acid by the SiC/graphene catalyst. Environ. Sci. Technol. 2016, 50, 58575863.

2. Wang, Y.; Zhang, P., Photocatalytic decomposition of perfluorooctanoic acid (PFOA) by TiO2 in the presence of oxalic acid. J. Hazard. Mater. 2011, 192, 1869-1875.

3. Sansotera, M.; Persico, F.; Pirola, C.; Navarrini, W.; Di Michele, A.; Bianchi, C. L., Decomposition of perfluorooctanoic acid photocatalyzed by titanium dioxide: Chemical modification of the catalyst surface induced by fluoride ions. Appl. Catal. B. 2014, 148-149, 29-35.

4. Chen, Y. C.; Lo, S. L.; Kuo, J., Effects of titanate nanotubes synthesized by a microwave hydrothermal method on photocatalytic decomposition of perfluorooctanoic acid. Water. Res. 2011, 45, 4131-4140.

5. Chen, M.-J.; Lo, S.-L.; Lee, Y.-C.; Kuo, J.; Wu, C.-H., Decomposition of perfluorooctanoic acid by ultraviolet light irradiation with $\mathrm{Pb}$-modified titanium dioxide. J. Hazard. Mate. 2016, 303, 111-118.

6. Li, M.; Yu, Z.; Liu, Q.; Sun, L.; Huang, W., Photocatalytic decomposition of perfluorooctanoic acid by noble metallic nanoparticles modified TiO2. Chem. Eng. J. 2016, 286, 232-238.

7. Chen, M.-J.; Lo, S.-L.; Lee, Y.-C.; Huang, C.-C., Photocatalytic decomposition of perfluorooctanoic acid by transition-metal modified titanium dioxide. J. Hazard. Mater. 2015, $288,168-175$.

8. Shang, E.; Li, Y.; Niu, J.; Li, S.; Zhang, G.; Wang, X., Photocatalytic degradation of perfluorooctanoic acid over $\mathrm{Pb}-\mathrm{BiFeO} 3 / \mathrm{rGO}$ catalyst: Kinetics and mechanism. Chemosphere 2018, 211, 34-43.

9. Song, Z.; Dong, X.; Fang, J.; Xiong, C.; Wang, N.; Tang, X., Improved photocatalytic degradation of perfluorooctanoic acid on oxygen vacancies-tunable bismuth oxychloride nanosheets prepared by a facile hydrolysis. J. Hazard. Mater. 2019, 377, 371-380.

10. Sahu, S. P.; Qanbarzadeh, M.; Ateia, M.; Torkzadeh, H.; Maroli, A. S.; Cates, E. L., Rapid degradation and mineralization of perfluorooctanoic acid by a new petitjeanite Bi3O $(\mathrm{OH})(\mathrm{PO} 4) 2$ microparticle ultraviolet photocatalyst. Environ. Sci. Technol. Lett. 2018, 5, 533538.

11. Zhao, B.; Lv, M.; Zhou, L., Photocatalytic degradation of perfluorooctanoic acid with $\beta$ $\mathrm{Ga} 2 \mathrm{O} 3$ in anoxic aqueous solution. J. Environ. Sci. 2012, 24, 774-780.

12. Huang, D.; de Vera, G. A.; Chu, C.; Zhu, Q.; Stavitski, E.; Mao, J.; Xin, H.; Spies, J. A.; Schmuttenmaer, C. A.; Niu, J., Single-atom Pt catalyst for effective C-F bond activation via hydrodefluorination. ACS Catal. 2018, 8, 9353-9358. 
13. Li, Z.; Zhang, P.; Shao, T.; Li, X., In2O3 nanoporous nanosphere: a highly efficient photocatalyst for decomposition of perfluorooctanoic acid. Appl. Catal. B. 2012, 125, 350-357.

14. Li, X.; Zhang, P.; Jin, L.; Shao, T.; Li, Z.; Cao, J., Efficient photocatalytic decomposition of perfluorooctanoic acid by indium oxide and its mechanism. Environ. Sci. Technol. 2012, 46, $5528-5534$.

15. Xu, J.; Wu, M.; Yang, J.; Wang, Z.; Chen, M.; Teng, F., Efficient photocatalytic degradation of perfluorooctanoic acid by a wide band gap p-block metal oxyhydroxide $\mathrm{InOOH}$. Appl. Surf. Sci. 2017, 416, 587-592.

16. Fu, X.; Hu, Y.; Yang, Y.; Liu, W.; Chen, S., Ball milled h-BN: An efficient holes transfer promoter to enhance the photocatalytic performance of TiO2. J. Hazard. Mater. 2013, 244-245, $102-110$.

17. Ding, Y.; Torres-Davila, F.; Khater, A.; Nash, D.; Blair, R.; Tetard, L., Defect engineering in Boron Nitride for catalysis. MRS Commun. 2018, 8, 1236-1243.

18. Long, M.; Brame, J.; Qin, F.; Bao, J.; Li, Q.; Alvarez, P. J., Phosphate changes effect of humic acids on $\mathrm{TiO} 2$ photocatalysis: from inhibition to mitigation of electron-hole recombination. Environ. Sci. Technol. 2016, 51, 514-521.

19. Liu, D.; Xiu, Z.; Liu, F.; Wu, G.; Adamson, D.; Newell, C.; Vikesland, P.; Tsai, A.L.; Alvarez, P. J., Perfluorooctanoic acid degradation in the presence of Fe (III) under natural sunlight. J. Hazard. Mater. 2013, 262, 456-463.

20. Qureshi, M.; Takanabe, K., Insights on measuring and reporting heterogeneous photocatalysis: efficiency definitions and setup examples. Chem. Mater. 2017, 29, 158-167.

21. Kisch, H.; Bahnemann, D., Best Practice in Photocatalysis: Comparing Rates or Apparent Quantum Yields? J. Phy. Chem. Lett. 2015, 6, 1907-1910.

22. Goto, H.; Hanada, Y.; Ohno, T.; Matsumura, M., Quantitative analysis of superoxide ion and hydrogen peroxide produced from molecular oxygen on photoirradiated $\mathrm{TiO} 2$ particles. $J$. Catal. 2004, 225, 223-229.

23. Bolton, J. R.; Stefan, M. I.; Shaw, P.-S.; Lykke, K. R., Determination of the quantum yields of the potassium ferrioxalate and potassium iodide-iodate actinometers and a method for the calibration of radiometer detectors. J. Photochem. Photobiol. A. 2011, 222, 166-169.

24. O'Neal Tugaoen, H.; Garcia-Segura, S.; Hristovski, K.; Westerhoff, P., Compact lightemitting diode optical fiber immobilized $\mathrm{TiO} 2$ reactor for photocatalytic water treatment. Sci. Total Environ. 2018, 613-614, 1331-1338. 